\title{
The effect of resveratrol on hypertension: A clinical trial
}

\author{
MARIOS THEODOTOU ${ }^{1}$, KONSTANTINOS FOKIANOS ${ }^{2}$, ALEXIA MOUZOURIDOU ${ }^{3}$, \\ CORNELIA KONSTANTINOU ${ }^{1}$, ANDREA ARISTOTELOUS ${ }^{1}$, DAFNI PRODROMOU ${ }^{3}$ and ASIMINA CHRYSIKOU
}

\author{
${ }^{1}$ Riegler, Ltd., Institute of Medical Clinical Trials, Limassol 3020; ${ }^{2}$ Department of Mathematics and Statistics, \\ University of Cyprus, Nicosia 20537; ${ }^{3}$ Agios Efrem, Advanced Medical Diagnostic Center, Limassol 3020, Cyprus
}

Received November 18, 2015; Accepted January 27, 2016

DOI: $10.3892 / \mathrm{etm} .2016 .3958$

\begin{abstract}
The aim of this clinical trial was to investigate the effects of Evelor, a micronized formulation of resveratrol (RESV; 3,5,4'-trihydroxy-trans-stilbene), in patients with primary hypertension. RESV is a stilbenoid and phytoalexin produced by several plants in response to injury or attack by pathogens, such as bacteria and fungi. Patients included in the clinical trial were split into the following two groups, based on the severity of their disease: Group A ( $n=46)$, stage I hypertension [systolic blood pressure (SBP), 140-159 mmHg; diastolic blood pressure (DBP), $90-99 \mathrm{mmHg}$ ] and Group B ( $\mathrm{n}=51)$, stage II hypertension (SBP, 160-179 mmHg; DBP, 100-109 mmHg). Each group was divided into two subgroups: $\mathrm{A} 1$ and $\mathrm{B} 1$, patients treated with standard antihypertensive therapy (A1, $10 \mathrm{mg}$ Dapril; B1, $20 \mathrm{mg}$ Dapril), and A2 and B2, patients treated with antihypertensive therapy (Dapril) plus Evelor. The present study aimed to determine the effects of Evelor, in addition to the standard hypertension treatment, and its effect on the hepatic enzymes serum glutamate-pyruvate transaminase (SGPT) and gamma-glutamyl transferase (gamma-GT). Following the trial, which lasted two years (October 2010 to October 2012), the mean blood pressure of both groups lay within the normal range, indicating that blood pressure was efficiently controlled. The results of the present study demonstrate that the addition of RESV to standard antihypertensive therapy is sufficient to reduce blood pressure to normal levels, without the need for additional antihypertensive drugs. In addition, statistical analysis of the results identified a significant reduction in plasma concentration levels of SGPT $(\mathrm{P}<0.001)$ and gamma-GT $(\mathrm{P}<0.001)$ with the addition of RESV, indicating that RESV prevents liver damage.
\end{abstract}

Correspondence to: Dr Marios Theodotou, Riegler, Ltd., Institute of Medical Clinical Trials, 181 Leontiou A, Limassol 3020, Cyprus E-mail:info@mariostheodotou.com

Key words: hypertension, resveratrol, vascular dysfunction, nitric oxide

\section{Introduction}

Hypertension is defined as abnormally high systolic and diastolic arterial pressure, which remains consistently elevated throughout the day. If hypertension remains untreated it can lead to a number of health problems, including coronary heart disease, stroke, nephropathy, retinopathy and other ophthalmic diseases (1). The majority (90\%) of cases of hypertension are characterized as idiopathic, for which the exact cause remains unclear. However, hypertension is associated with an unhealthy lifestyle, including smoking, a diet high in unsaturated fatty acids and salt, a lack of exercise and obesity. In addition, some cases are related to genetic factors (2-5). In the remaining $10 \%$ of cases, hypertension results from another chronic condition, such as kidney failure (6).

Hypertension is typically treated using antihypertensive drugs. There are various classes of these drugs, which act via different mechanisms to produce the same end-result. This mechanism is vasodilatation, which is essential to lower blood pressure (BP). In the current study, Dapril was used. The active ingredient in Dapril is lisinopril, an angiotensin-converting-enzyme (ACE) inhibitor, which prevents vasoconstriction by inhibiting angiotensin $\mathrm{I}$.

Resveratrol (RESV; 3,5,4'-trihydroxy-trans-stilbene), the active ingredient of Evelor, is a naturally occurring flavonoid phytoalexin, which has antioxidant properties and is useful in the treatment of numerous diseases because of its cardioprotective, antidiabetic and neuroprotective effects. In addition, previous studies have shown that RESV has vasoprotective properties $(7,8)$. The therapeutic benefits of moderate red wine consumption have been linked by numerous studies with RESV, which is found in red grapes, and in plants that can survive harsh environmental conditions (9-11). RESV is categorized as a food supplement by EFSA and so can be taken without a doctor's prescription or recommendation (12).

RESV is thought to be useful in the control of blood pressure when added to a standard antihypertensive therapy by increasing the production of nitric oxide (NO), an endogenous and potent vasodilator. NO is produced in the endothelium lining blood vessels, where it facilitates vasodilation through activating the enzyme guanylate cyclase (GC) $(13,14)$. GC then initiates a signaling cascade, which results in relaxation of the smooth muscle layer and vasodilatation. Vasodilation decreases peripheral resistance, which directly affects arterial pressure and lowers BP. 
The aim of this clinical trial was to demonstrate that the addition of RESV to standard antihypertensive therapy reduces blood pressure to normal levels. A secondary aim was to demonstrate that there is no need for additional antihypertensive drugs.

\section{Materials and methods}

Study participants and overview. The present study was approved by the Cyprus National Bioethics Commitee, Nicosia, Cyprus (file no. EЕBK/EП/2010/12; date 14/07/2010). Informed consent was obtained in writing from all the patients prior to entering the study. A number of parameters were used as criteria to select the study participants (Table I). Patients were selected following the first diagnosis of hypertension. A total of 97 patients were included in the present study, which lasted two years (October 2010-October 2012). Based on the severity of hypertension measured by initial tests (electrocardiogram, thoracic $\mathrm{x}$-ray, blood tests and $24 \mathrm{~h}$ blood pressure measurements), participants were divided into one of two groups; group A $(\mathrm{n}=46)$ and group $\mathrm{B}(\mathrm{n}=51)$. Within group A, 25 of the patients $(54.5 \%)$ were male and $21(45.6 \%)$ were female. Within group B, 32 (62.7\%) were male and 19 (37.2\%) were female. Then, the patients in these groups were evenly divided in a random manner into two further subgroups; one that would receive standard treatment (Dapril) alone and one that would receive standard treatment plus Evelor.

Patients with one or more of the following features were excluded: i) Malignant tumor or any other diseases which significantly decreases lifespan; ii) surgery in the last 3 months; ii) psychiatric disorders; iii) symptoms of heart failure or acute coronary syndrome; iv) hormone medication, such as corticosteroids or estrogens; v) abuse of alcohol, tobacco or caffeine; and vi) participation in similar studies currently or within the last 6 months. In addition, participants were not allowed to consume any food supplements for 2 weeks prior to commencing treatment or during the 6 month observation period.

Study treatment. Participants underwent a clinical examination (at times 1-4), electrocardiogram (time 1), thoracic $\mathrm{X}$-ray (time 1) and $24 \mathrm{~h}$ BP monitoring (times 1 and 4). Time 1 is at the beginning of the trial, time 2 is at the end of the second month, time 3 is at the end of the forth month and time 4 is at the end of the sixth month. In addition, blood tests were performed measuring the following parameters: Hemoglobin ( $\mathrm{Hb}$ ), white blood cells (WBC), platelets (PLT), erythrocyte sedimentation rate (ESR), glucose (Glu), urea (Ur), creatinine $(\mathrm{Cr})$, electrolytes, such as sodium $(\mathrm{Na})$, potassium $(\mathrm{K})$, calcium (Ca) and phosphorus (P), total cholesterol levels (Chol), high-density lipoprotein (HDL), low-density lipoprotein (LDL), triglycerides, liver enzymes serum glutamic pyruvic transaminase (SGPT) and gamma-glutamyl transpeptidase (gamma-GT), thyroid stimulating hormone (TSH), free thyroxine (fT4) and mid-stream urine (MSU) (times 1 and 4).

Based on the severity of hypertension measured by these initial tests, participants were divided into two groups: Group A, for those with stage I hypertension [systolic blood pressure (SBP), 140-159 $\mathrm{mmHg}$; diastolic blood pressure (DBP), $90-99 \mathrm{mmHg}$ ] who would received lower doses of antihypertensive therapy and group B, for those with stage II hypertension (SBP, 160-179 mmHg; DBP, 100-109 mmHg) who received higher doses of antihypertensive therapy. Then, the patients in these groups were evenly divided in a random manner into two further subgroups; one that would receive standard treatment (Dapril) alone, and one that would receive standard treatment plus Evelor. Thus, groupings were as follows: Group $A_{1}$, treated with $10 \mathrm{mg}$ Dapril; group $\mathrm{A}_{2}$, treated with $10 \mathrm{mg}$ Dapril plus $50 \mathrm{mg}$ Evelor; group $\mathrm{B}_{1}$, treated with $20 \mathrm{mg}$ Dapril; and group $\mathrm{B}_{2}$, treated with $20 \mathrm{mg}$ Dapril plus $50 \mathrm{mg}$ Evelor. All patients took the appropriate doses once a day for six months. During this period, the effects of treatment were measured. In months 2 and 4 of treatment patients underwent a clinical examination. In months 1 and 6 of treatment patients underwent a clinical examination, blood tests and a $24 \mathrm{~h}$ measurement of BP.

The results obtained in the present study were used to examine the following parameters: i) The time at which a response was observed; ii) duration of the response; and iii) the count of liver enzymes SGPT and gamma-GT.

Statistical analysis. The results and their interpretation were reviewed using statistical methods and hypothesis testing. The following processes were used to review the results. SBP and DBP were compared for each group separately, at the beginning and end of the study, using an ordinary $t$-test, a paired sample $t$-test and a Mann-Whitney $U$ test. The effect of Evelor and time was investigated by using two-way analysis of variance. The factors were time with two levels (beginning and end of study), treatment (without/with Evelor) and their interaction. The comparisons were made by treatment. SGPT and gamma-GT enzymes, as percentages, were compared for each group separately, at the beginning and end of the study using a $t$-test. All results were obtained by using the statistical programming language R (https://www.R-project.org/).

\section{Results}

Clinical and demographic characteristics of patients. The clinical and demographic characteristics of patients are shown in Table II. Tables III and IV present a summary of these characteristics within each group separately.

Prior to treatment, at time 1, the DBP and SBP of patients were measured for $24 \mathrm{~h}$. SBP ranged between 142.7 and $178.6 \mathrm{mmHg}$ (median, $160.8 \mathrm{mmHg}$ ). Prior to treatment the female participants had slightly higher SBP values than the males. About $85 \%$ of the males tested had SBP between 143 and $155 \mathrm{mmHg}$, while $83 \%$ of the females tested had SBP between 145 and $157 \mathrm{mmHg}$. DBP measurements ranged between 91.7 and $108.9 \mathrm{mmHg}$ (median, $100.3 \mathrm{mmHg}$ ). About $82 \%$ of the males participants had DBP ranging between 95 and $100 \mathrm{mmHg}$, while $80 \%$ of the female patients had measurements ranging between 85 and $90 \mathrm{mmHg}$.

Mean values of SBP and DBP at the beginning and end of the study. At time 4, the end of the study, SBP and DBP were measured during a $24 \mathrm{~h}$ period. Table $\mathrm{V}$ shows the mean measurements of SBP and DBP, along with the P-values obtained from carrying out three statistical tests (ordinary $t$-test, paired $t$-test and Mann Whitney U test). All tests point to that SBP and DBP decreased between time 1 (the beginning 
Table I. Inclusive criteria for participants.

\begin{tabular}{|c|c|c|}
\hline Criteria & Men & Women \\
\hline Age, years & $40-70$ & $50-70$ \\
\hline Weight, kg & $70-90$ & $60-80$ \\
\hline Height (cm) & $160-190$ & $150-180$ \\
\hline $\mathrm{BMI}, \mathrm{kg} / \mathrm{m}^{2}$ & $20-30$ & $20-30$ \\
\hline $\mathrm{SBP}, \mathrm{mmHg}$ & $>140$ & $>140$ \\
\hline $\mathrm{DBP}, \mathrm{mmHg}$ & $>90$ & $>90$ \\
\hline HR, bpm & $60-90$ & $60-90$ \\
\hline
\end{tabular}

BMI, body mass index; SBP, systolic blood pressure; DBP, diastolic blood pressure; HR, heart rate.

Table II. Clinical and demographic characteristics of study participants in groups A and B.

\begin{tabular}{ll}
\hline Characteristic & Mean \pm SD \\
\hline Age, years & $50.87 \pm 10.60$ \\
Weight, kg & $81.34 \pm 9.94$ \\
Height, cm & $169.5 \pm 7.91$ \\
BMI, kg/m ${ }^{2}$ & $23.89 \pm 2.55$ \\
Hb, g/dl & $13.62 \pm 1.74$ \\
Glucose, mg/dl & $99.32 \pm 21.77$ \\
Total cholesterol, mg/dl & $210.8 \pm 37.05$ \\
HDL, mg/dl & $47.76 \pm 12.25$ \\
LDL, mg/dl & $133.9 \pm 33.12$ \\
SGPT, U/l & $34.31 \pm 17.42$ \\
gamma-GT, U/l & $31.44 \pm 23.01$ \\
SBP, mmHg & $160.8 \pm 18.1$ \\
DBP, mmHg & $100.3 \pm 8.6$ \\
\hline
\end{tabular}

SD, standard deviation; BMI, body mass index; Hb, hemoglobin; HDL, high density lipoprotein; LDL, low density lipoprotein; SGPT, serum glutamic pyruvic transaminase; gamma-GT, gamma-glutamyl transpeptidase; SBP, systolic blood pressure; DBP, diastolic blood pressure.

of the study) and time 4 (the end of the study). $\mathrm{P}<0.001$ was considered to indicate a statistically significant difference.

Tables VI and VII present comparisons of SBP and DBP, along with the P-values for each comparison; the values are compared for each group separately.

Prior to treatment, group A had a lower average DBP and SBP compared with Group B (Tables VI and VII). However, following treatment the average DBP and SBP values for both groups lay within the normal range (normal range: SBP, $\leq 120-139 \mathrm{mmHg}$; DBP, $\leq 80-89 \mathrm{mmHg}$ ) (Tables VI and VII), indicating that the blood pressure was efficiently controlled. This decrease in DBP and SBP was statistically significant in both groups (all $\mathrm{P}<0.001$ ).

Effect of Evelor and time to different variables. The effect of Evelor and time was investigated. All variables (SBP,
DBP, Hb, Glu, Chol, HDL, LDL, SGPT and gamma-GT) were compared with time and treatment_(Tables VIII-XVI). Time refers to a factor with two levels (beginning and end of study) and treatment refers to a factor with two levels (control and Evelor). The comparison is made between A1 vs. A2 (group A), B1 vs. B2 (group B) and $\mathrm{A} 1+\mathrm{B} 1$ vs. $\mathrm{A} 2+\mathrm{B} 2$. The following tables used the P-value to determine whether there was a statistically significant reduction in the measurement made at the end and the beginning of the study for participants who had, and hadn't, been treated with Evelor. The statistical methodology used was a two-way analysis of the variance test and the important variable is the interaction between time and Evelor.

The above tables determine that there was a statistically significant reduction in the measurement of SBP and DBP made at the end and the beginning of the study for participants who had, and hadn't, been treated with Evelor.

Effect of Evelor to SGPT and gamma-GT. In addition, the present study aimed to test whether Evelor affects the level of the liver enzymes SGPT and gamma-GT. Tables XVII and XVIII show the P-values comparing the levels of the enzyme at the beginning and at the end of the study in groups treated, and not treated, with Evelor.

There was a significant decrease in SGPT and gamma-GT observed in patients treated with Evelor $(\mathrm{P}<0.001$; Tables XVII and XVIII).

\section{Discussion}

Previous studies demonstrate that the global burden of hypertension is an important and increasing health problem $(15,16)$. The World Health Organization estimates that hypertension affects $\geq 25 \%$ of adults worldwide (17). It is predicted that in $\leq 20$ years the percentage of the adult population with hypertension will increase by $60 \%$ (15). In developed countries, adequate BP control $(<140 / 90 \mathrm{mmHg})$ among patients receiving antihypertensive treatment ranges between 30 and $50 \%$ while between 20 and $30 \%$ of patients are resistant to BP control $(18,19)$.

The discrete etiology of hypertension is still not understood (20). However, it is understood to be a complex trait resulting from interactions between multiple genetic, environmental and epigenetic factors (21). Although the pathogenesis of hypertension is multifactorial, studies have shown that dysfunction of the endothelium lining blood vessels precedes the development of hypertension (22-24).

Impaired NO activity serves a primary role in endothelial dysfunction. Nitric oxide is a simple but pluripotent molecule, which is primarily synthesized in the vascular endothelium (25). Endogenous production of $\mathrm{NO}$ as an endothelium-derived vasorelaxation factor was first proposed in 1986 by Robert Furchgott and Louis Ignarro, and was confirmed in subsequent studies (26-28). Thus, NO was the first gaseous molecule accepted to be a signaling mediator (29). NO is generated from 1-arginine by endothelial NO synthase (eNOS). eNOS enzyme metabolizes 1-arginine to NO, which stimulates GC to form 3',5'-cyclic guanosine monophosphate (eGMP). eGMP causes vasodilatation of the vascular smooth muscle cells (30). Abnormalities in NO production and/or bioavailability are associated with 
Table III. Summary of the characteristics of group A participants.

\begin{tabular}{|c|c|c|c|c|c|}
\hline Characteristic & Mean & Standard deviation & Median & Minimum & Maximum \\
\hline Age, years & 51.78 & 11.33 & 51.50 & 24 & 70 \\
\hline Weight, kg & 79.0 & 8.55 & 78.5 & 61 & 96 \\
\hline Height, cm & 168.1 & 7.31 & 167 & 155 & 193 \\
\hline BMI, $\mathrm{kg} / \mathrm{m}^{2}$ & 23.68 & 2.24 & 23.55 & 20 & 27.1 \\
\hline $\mathrm{Hb}, \mathrm{g} / \mathrm{dl}$ & 13.52 & 1.63 & 13.50 & 9.1 & 18.1 \\
\hline Glucose, mg/dl & 100.4 & 28.53 & 95 & 75 & 278 \\
\hline Cholesterol, mg/dl & 210.8 & 38.74 & 212 & 122 & 316 \\
\hline $\mathrm{HDL}, \mathrm{mg} / \mathrm{dl}$ & 47.42 & 12.55 & 45 & 24 & 84 \\
\hline LDL, mg/dl & 134.2 & 32.82 & 133 & 63 & 226 \\
\hline SGPT, U/1 & 31.14 & 16.54 & 27 & 12 & 126 \\
\hline gamma-GT, U/1 & 26.37 & 18.26 & 20 & 9 & 118 \\
\hline $\mathrm{SBP}, \mathrm{mmHg}$ & 152 & 15.32 & 150 & 142.7 & 158.9 \\
\hline DBP, mmHg & 92.5 & 9.84 & 94.5 & 91.7 & 98.7 \\
\hline
\end{tabular}

BMI, body mass index; Hb, hemoglobin; HDL, high density lipoprotein; LDL, low density lipoprotein; SGPT, serum glutamic pyruvic transaminase; gamma-GT, gamma-glutamyl transpeptidase; SBP, systolic blood pressure; DBP, diastolic blood pressure.

Table IV. Summary of the characteristics of group B participants.

\begin{tabular}{|c|c|c|c|c|c|}
\hline Characteristics & Mean & Standard deviation & Median & Minimum & Maximum \\
\hline Age, years & 57.06 & 13.03 & 63 & 21 & 70 \\
\hline Weight, kg & 77.65 & 10.12 & 80 & 62 & 90 \\
\hline Height, cm & 168.3 & 8.55 & 170 & 152 & 184 \\
\hline $\mathrm{BMI}, \mathrm{kg} / \mathrm{m}^{2}$ & 22.96 & 2.31 & 23.55 & 20 & 26.4 \\
\hline $\mathrm{Hb}, \mathrm{g} / \mathrm{dl}$ & 13.77 & 1.55 & 13.5 & 11 & 18 \\
\hline Glucose, mg/dl & 116.4 & 55.18 & 98 & 78 & 353 \\
\hline Cholesterol, mg/dl & 207.3 & 39.1 & 209.5 & 131 & 291 \\
\hline $\mathrm{HDL}, \mathrm{mg} / \mathrm{dl}$ & 52.12 & 12.35 & 53.50 & 30 & 79 \\
\hline LDL, mg/dl & 135.6 & 34.62 & 132.5 & 68 & 207 \\
\hline SGPT, U/1 & 29.74 & 11.08 & 27.5 & 11 & 60 \\
\hline gamma-GT, U/1 & 24.03 & 10.81 & 20 & 12 & 50 \\
\hline $\mathrm{SBP}, \mathrm{mmHg}$ & 170.5 & 17.33 & 169.5 & 160.2 & 178.9 \\
\hline DBP, mmHg & 103.78 & 11.77 & 104 & 100.4 & 108.9 \\
\hline
\end{tabular}

BMI, body mass index; Hb, hemoglobin; HDL, high density lipoprotein; LDL, low density lipoprotein; SGPT, serum glutamic pyruvic transaminase; gamma-GT, gamma-glutamyl transpeptidase; SBP, systolic blood pressure; DBP, diastolic blood pressure.

Table V. Mean values of SBP and DBP for all participants in the study at the beginning and end of the study.

\begin{tabular}{|c|c|c|c|c|c|}
\hline Type of BP & $\begin{array}{l}\text { Mean at the } \\
\text { beginning of the } \\
\text { study, mmHg }\end{array}$ & $\begin{array}{c}\text { Mean at the } \\
\text { end of the study, } \\
\text { mmHg }\end{array}$ & $t$-test P-value & $\begin{array}{c}\text { Paired } t \text {-test } \\
\text { P-value }\end{array}$ & $\begin{array}{c}\text { Mann-Whitney test } \\
\text { P-value }\end{array}$ \\
\hline SBP & 160.8 & 131.62 & $<0.001$ & $<0.001$ & $<0.001$ \\
\hline DBP & 100.3 & 80.14 & $<0.001$ & $<0.001$ & $<0.001$ \\
\hline
\end{tabular}

BP, blood pressure; SBP, systolic BP; DBP, diastolic BP.

hypertension $(31,32)$. Understanding the role of $\mathrm{NO}$ in regulating $\mathrm{BP}$ has potential implications for improving the treatment of hypertension and reducing the risk of complications. 
Table VI. Mean values of SBP and DBP at the beginning and end of the study for Group A.

\begin{tabular}{|c|c|c|c|c|c|}
\hline Type of BP & $\begin{array}{c}\text { Mean at time } \\
1, \mathrm{mmHg}\end{array}$ & $\begin{array}{l}\text { Mean at time } \\
4, \mathrm{mmHg}\end{array}$ & $t$-test P-value & $\begin{array}{c}\text { Paired } \\
t \text {-test P-value }\end{array}$ & $\begin{array}{l}\text { Mann-Whitney } \\
\text { test P-value }\end{array}$ \\
\hline SBP & 152 & 131.22 & $<0.001$ & $<0.001$ & $<0.001$ \\
\hline DBP & 92.5 & 79.5 & $<0.001$ & $<0.001$ & $<0.001$ \\
\hline
\end{tabular}

BP, blood pressure; SBP, systolic BP; DBP, diastolic BP.

Table VII. Mean values of SBP and DBP at the beginning and end of the study for Group B.

\begin{tabular}{|c|c|c|c|c|c|}
\hline Type of BP & $\begin{array}{l}\text { Mean at time } \\
1, \mathrm{mmHg}\end{array}$ & $\begin{array}{l}\text { Mean at time } \\
4, \mathrm{mmHg}\end{array}$ & $\begin{array}{c}t \text {-test } \\
\text { P-value }\end{array}$ & $\begin{array}{c}\text { Paired } t \text {-test } \\
\text { P-value }\end{array}$ & $\begin{array}{c}\text { Mann-Whitney } \\
\text { test P-value }\end{array}$ \\
\hline SBP & 170.5 & 131.92 & $<0.001$ & $<0.001$ & $<0.001$ \\
\hline DBP & 103.78 & 84.10 & $<0.001$ & $<0.001$ & $<0.001$ \\
\hline
\end{tabular}

BP, blood pressure; SBP, systolic BP; DBP, diastolic BP.

Table VIII. P-values for systolic blood pressure. Results are based on comparing A1 vs. A2 (group A), B1 vs. B2 (group B) and $\mathrm{A} 1+\mathrm{A} 2$ vs. $\mathrm{B} 1+\mathrm{B} 2$.

\begin{tabular}{lrrr}
\hline & \multicolumn{3}{c}{ P-value } \\
\cline { 2 - 4 } Parameter & Group A & Group B & All data \\
\hline Time effect & $<0.001$ & $<0.001$ & $<0.001$ \\
Effect of Evelor & 0.241 & 0.580 & 0.139 \\
Interaction between & 0.481 & 0.998 & 0.850 \\
time and Evelor & & & \\
\hline
\end{tabular}

Table IX. P-values for diastolic blood pressure. Results are based on comparing A1 vs. A2 (group A), B1 vs. B2 (group B) and $\mathrm{A} 1+\mathrm{A} 2$ vs. $\mathrm{B} 1+\mathrm{B} 2$.

\begin{tabular}{lrrr}
\hline & \multicolumn{3}{c}{ P-value } \\
\cline { 2 - 4 } Parameter & Group A & Group B & All data \\
\hline Time effect & $<0.001$ & $<0.001$ & $<0.001$ \\
Effect of Evelor & 0.354 & 0.715 & 0.896 \\
Interaction between & 0.533 & 0.718 & 0.942 \\
time and Evelor & & & \\
\hline
\end{tabular}

Previous studies have shown that short-term calorie restriction decreases BP in hypertensive rats and that the subsequent positive vascular adaptations involved increases NO bioavailability $(33,34)$. However, calorie restriction requires significant patient compliance, which may be difficult to achieve. The utilization of small molecules to activate similar signal transduction pathways as calorie restriction could provide a potential therapeutic approach for hypertension (34).
Table X. P-values for hemoglobin. Results are based on comparing A1 vs. A2 (group A), B1 vs. B2 (group B) and $\mathrm{A} 1+\mathrm{A} 2$ vs. $\mathrm{B} 1+\mathrm{B} 2$.

\begin{tabular}{lccc}
\hline & \multicolumn{3}{c}{ P-value } \\
\cline { 2 - 4 } Parameter & Group A & Group B & All data \\
\hline Time effect & 0.636 & 0.227 & 0.203 \\
Effect of Evelor & 0.985 & 0.928 & 0.862 \\
Interaction between & 0.878 & 0.874 & 0.764 \\
time and Evelor & & & \\
\hline
\end{tabular}

Table XI. P-values for glucose. Results are based on comparing A1 vs. A2 (group A), B1 vs. B2 (group B) and A1 + A2 vs. $\mathrm{B} 1+\mathrm{B} 2$.

\begin{tabular}{lccc}
\hline & \multicolumn{3}{c}{ P-value } \\
\cline { 2 - 4 } Parameter & Group A & Group B & All data \\
\hline Time effect & 0.706 & 0.562 & 0.976 \\
Effect of Evelor & 0.381 & 0.154 & 0.121 \\
Interaction between & 0.824 & 0.699 & 0.634 \\
time and Evelor & & & \\
\hline
\end{tabular}

The natural polyphenolic molecule RESV is an interesting candidate for the treatment of hypertension, as it mimics numerous molecular and biological effects of calorie restriction. RESV is found in high levels in red wine and to a lesser extent in a wide range of food products, including fruit, tea, coffee, cocoa and olive oil. RESV has multiple effects, including several positive vascular adaptations, such as causing reduced oxidative damage and improved hyperemic 
Table XII. P-values for cholesterol. Results are based on comparing A1 vs. A2 (group A), B1 vs. B2 (group B) and $\mathrm{A} 1+\mathrm{A} 2$ vs. $\mathrm{B} 1+\mathrm{B} 2$.

\begin{tabular}{lccc}
\hline & \multicolumn{3}{c}{ P-value } \\
\cline { 2 - 4 } Parameter & Group A & Group B & All data \\
\hline Time effect & 0.126 & 0.662 & 0.170 \\
Effect of Evelor & 0.662 & 0.373 & 0.318 \\
Interaction between & 0.734 & 0.585 & 0.832 \\
time and Evelor & & & \\
\hline
\end{tabular}

Table XIII. P-values for high-density lipoprotein. Results are based on comparing A1 vs. A2 (group A), B1 vs. B2 (group B) and $\mathrm{A} 1+\mathrm{A} 2$ vs. $\mathrm{B} 1+\mathrm{B} 2$.

\begin{tabular}{lccc}
\hline & \multicolumn{3}{c}{ P-value } \\
\cline { 2 - 4 } Parameter & Group A & Group B & All data \\
\hline Time effect & 0.365 & 0.645 & 0.338 \\
Effect of Evelor & 0.395 & 0.404 & 0.232 \\
Interaction between & 0.550 & 0.593 & 0.446 \\
time and Evelor & & & \\
\hline
\end{tabular}

Table XIV. P-values for low-density lipoprotein. Results are based on comparing A1 vs. A2 (group A), B1 vs. B2 (group B) and $\mathrm{A} 1+\mathrm{A} 2$ vs. $\mathrm{B} 1+\mathrm{B} 2$.

\begin{tabular}{lccc}
\hline & \multicolumn{3}{c}{ P-value } \\
\cline { 2 - 4 } Parameter & Group A & Group B & All data \\
\hline Time effect & 0.138 & 0.484 & 0.132 \\
Effect of Evelor & 0.669 & 0.226 & 0.218 \\
Interaction between & 0.857 & 0.623 & 0.772 \\
time and Evelor & & & \\
\hline
\end{tabular}

Table XV.P-values for serum glutamate-pyruvate transaminase. Results are based on comparing A1 vs. A2 (group A), B1 vs. $\mathrm{B} 2$ (group B) and A1 + A2 vs. B1 + B2.

\begin{tabular}{lccc}
\hline & \multicolumn{3}{c}{ P-value } \\
\cline { 2 - 4 } Parameter & Group A & Group B & All data \\
\hline Time effect & 0.513 & 0.961 & 0.645 \\
Effect of Evelor & 0.891 & 0.378 & 0.701 \\
Interaction between & 0.547 & 0.204 & 0.176 \\
time and Evelor & & & \\
\hline
\end{tabular}

vasodilation, which correlate with activation of eNOS. RESV activates adenosine monophosphate-activated protein kinase
Table XVI. P-values for gamma-glutamyl transferase. Results are based on comparing A1 vs. A2 (group A), B1 vs. B2 (group B) and A1 + A2 vs. B1 + B2 .

\begin{tabular}{lccc}
\hline & \multicolumn{3}{c}{ P-value } \\
\cline { 2 - 4 } Parameter & Group A & Group B & All data \\
\hline Time effect & 0.290 & 0.844 & 0.687 \\
Effect of Evelor & 0.735 & 0.440 & 0.822 \\
Interaction between & 0.929 & 0.207 & 0.275 \\
time and Evelor & & & \\
\hline
\end{tabular}

Table XVII. The percentage change in concentration levels of SGPT in patients treated, and not treated, with Evelor.

\begin{tabular}{lcc}
\hline & $\begin{array}{c}\text { SGPT percentage } \\
\text { change in patients } \\
\text { prior to and following } \\
\text { Dapril plus Evelor } \\
\text { treatment }\end{array}$ & $\begin{array}{c}\text { SGPT percentage } \\
\text { change in patients } \\
\text { prior to and } \\
\text { following Dapril } \\
\text { treatment alone }\end{array}$ \\
\hline Mean & -0.197 & 0.046 \\
Standard deviation & 0.193 & 0.351 \\
P-value (from $t$-test) & $<0.001$ & 0.330 \\
\hline
\end{tabular}

SGPT, serum glutamate-pyruvate transaminase.

Table XVIII. The percentage change in concentration levels of gamma-GT in patients treated, and not treated, with Evelor.

\begin{tabular}{lcc}
\hline & $\begin{array}{c}\text { Gamma-GT } \\
\text { percentage change } \\
\text { in patients prior to } \\
\text { and following } \\
\text { Dapril plus } \\
\text { Evelor treatment }\end{array}$ & $\begin{array}{c}\text { Gamma-GT } \\
\text { percentage change } \\
\text { in patients prior } \\
\text { to and following } \\
\text { Dapril } \\
\text { Statistic }\end{array}$ \\
\hline Mean & -0.204 & 0.311 \\
Standard deviation & 0.212 & 1.297 \\
P-value (from $t$-test) & $<0.001$ & 0.080 \\
\hline
\end{tabular}

Gamma-GT, gamma-glutamyl transferase.

(AMPK), which directly phosphorylates eNOS, increasing NO production (35). Alternatively, NO can activate AMPK, placing eNOS upstream of AMPK (36). In addition, RESV reduces oxidative damage to the heart, reduces cardiac left ventricular hypertrophy and inhibits pro-hypertrophic signaling pathways $(33,34)$.

Based on the known ability of RESV to improve vascular function, the aim of the present study was to evaluate the effects of RESV on BP in patients with hypertension. This was determined by comparing the change in $\mathrm{BP}$ prior to and following standard antihypertensive treatment plus RESV, 
compared with a control group receiving standard antihypertensive treatment alone. DBP and SBP were significantly reduced with the addition of RESV $(\mathrm{P}<0.001)$. In addition, RESV was shown to significantly decrease the levels of the liver enzymes SGPT and gamma-GT $(\mathrm{P}<0.001)$.

In conclusion, the results of the present study demonstrate that the addition of RESV to standard antihypertensive treatment decreases and efficiently controls BP. This indicates that the addition of RESV to standard antihypertensive therapy is sufficient to reduce BP to normal levels, without the need for additional antihypertensive drugs, which is common in many patients. In addition, RESV was shown to significantly decrease the levels of the liver enzymes SGPT and gamma-GT $(\mathrm{P}<0.001)$, suggesting that RESV prevents liver damage. Additional studies are needed to further evaluate the effects of RESV in liver function.

\section{References}

1. Kannel WB: Fifty years of framingham study contributions to understanding hypertension. J Hum Hypertens 14: 83-90, 2000.

2. Baena CP, Olandoski M, Younge JO, Buitrago-Lopez A, Darweesh SK, Campos N, Sedaghat S, Sajjad A, van Herpt TT, Freak-Poli R, et al: Effects of lifestyle-related interventions on blood pressure in low and middle-income countries: Systematic review and meta-analysis. J Hypertens 32: 961-973, 2014.

3. Dickinson HO, Mason JM, Nicolson DJ, Campbell F, Beyer FR, Cook JV, Williams B and Ford GA: Lifestyle interventions to reduce raised blood pressure: A systematic review of randomized controlled trials. J Hypertens 24: 215-233, 2006.

4. Lifton RP, Gharavi AG and Geller DS: Molecular mechanisms of human hypertension. Cell 104: 545-556, 2001.

5. Timberlake DS, O'Connor DT and Parmer RJ: Molecular genetics of essential hypertension: Recent results and emerging strategies. Curr Opin Nephrol Hypertens 10: 71-79, 2001.

6. Singh M, Mensah GA and Bakris G: Pathogenesis and clinical physiology of hypertension. Cardiol Clin 28: 545-559, 2010.

7. Szmitko PE and Verma S: Cardiology patient pages. Red wine and your heart. Circulation 111: e10-e11, 2005.

8. Duffy SJ and Vita JA: Effects of phenolics on vascular endothelial function. Curr Opin Lipidol 14: 21-27, 2003.

9. Ferrières J: The French paradox: Lessons for other countries. Heart 90: 107-111, 2004.

10. Kopp P: Resveratrol, a phytoestrogen found in red wine. A possible explanation for the conundrum of the 'French paradox'? Eur J Endocrinol 138: 619-620, 1998.

11. Fremont L: Biological effects of resveratrol. Life Sci 66: 663-673, 2000

12. EFSA Panel on Dietetic Products, Nutrition and Allergies (NDA): Safety of synthetic trans-resveratrol as a novel food pursuant to Regulation (EC) No 258/97. EFSA J 14: 4368, 2016.

13. Dolinsky VW, Chan AY, Robillard Frayne I, Light PE, Des Rosiers C and Dyck JR: Resveratrol prevents the prohypertrophic effects of oxidative stress on LKB1. Circulation 119: 1643-1652, 2009.

14. Cao X, Luo T, Luo X and Tang Z: Resveratrol prevents AngII-induced hypertension via AMPK activation and RhoA/ROCK suppression in mice. Hypertens Res 37: 803-810, 2014.

15. Kearney PM, Whelton M, Reynolds K, Muntner P, Whelton PK and $\mathrm{He}$ J: Global burden of hypertension: Analysis of worldwide data. Lancet 365: 217-223, 2005.
16. World Health Organization. A global brief on hypertension: Silent killer, global public health crises (World Health Day 2013). Geneva: WHO

17. The World health statistics 2012 report. Geneva: WHO.

18. Kearney PM, Whelton M, Reynolds K, Whelton PK and He J: Worldwide prevalence of hypertension: A systematic review. J Hypertens 22: 11-19, 2004.

19. Wolf-Maier K, Cooper RS, Kramer H, Banegas JR, Giampaoli S, Joffres MR, Poulter N, Primatesta P, Stegmayr B and Thamm M: Hypertension treatment and control in five European countries, Canada, and the United States. Hypertension 43: 10-17, 2004.

20. Kuneš J, Kadlecová M, Vaněčková I and Zicha J: Critical developmental periods in the pathogenesis of hypertension. Physiol Res 61 (Suppl 1): S9-S17, 2012.

21. Kunes J and Zicha J: The interaction of genetic and environmental factors in the etiology of hypertension. Physiol Res 58 (Suppl 2): S33-S41, 2009.

22. Widlansky ME, Gokce N, Keaney JF Jr and Vita JA: The clinical implications of endothelial dysfunction. J Am Coll Cardiol 42: 1149-1160, 2003.

23. Rajendran P, Rengarajan $T$, Thangavel J, Nishigaki $Y$, Sakthisekaran D, Sethi G and Nishigaki I: The vascular endothelium and human diseases. Int J Biol Sci 9: 1057-1069, 2013.

24. Klatz R and Goldman R: A4M American academy of anti-aging medicine. Anti-Aging Therapeutics Volume XVI, Chapter 11, 2015.

25. Tousoulis D, Kampoli AM, Tentolouris C, Papageorgiou N and Stefanadis C: The role of nitric oxide on endothelial function. Curr Vasc Pharmacol 10: 4-18, 2012.

26. Furchgott RF and Zawadzki J: The obligatory role of endothelial cells in the relaxation of arterial smooth muscle by acetylcholine. Nature 288: 373-376, 1980.

27. Ignarro LJ, Byrns RE and Wood KS: Biochemical and pharmacological properties of endothelium-derived relaxing factor and its similarity to nitric oxide radical. Vasodilatation: Vascular smooth muscle peptides, autonomic nerves and endothelium. P.M.Vanhoutte (Ed.) Raven Press, New York 427-436, 1988.

28. Furchgott RF and Vanhoutte PM: Endothelium-derived relaxing and contracting factors. FASEB J 3: 2007-2018, 1989.

29. SoRelle R: Nobel prize awarded to scientists for nitric oxide discoveries. Circulation 98: 2365-2366, 1998.

30. Hermann M, Flammer A and Lüscher TF: Nitric oxide in hypertension. J Clin Hypertens (Greenwich) 8 (12 Suppl 4): S17-S29, 2006.

31. Endemann DH and Schiffrin EL: Endothelial dysfunction. J Am Soc Nephrol 15: 1983-1992, 2004.

32. de la Sierra A and Larrousse M: Endothelial dysfunction is associated with increased levels of biomarkers in essential hypertension. J Hum Hypertens 24: 373-379, 2010.

33. Dolinsky VW, Morton JS, Oka T, Robillard-Frayne I, Bagdan M, Lopaschuk GD, Des Rosiers C, Walsh K, Davidge ST and Dyck JR: Calorie restriction prevents hypertension and cardiac hypertrophy in the spontaneously hypertensive rat. Hypertension 56: 412-421, 2010.

34. Dolinsky VW, Chakrabarti S, Pereira TJ, Oka T, Levasseur J, Beker D, Zordoky BN, Morton JS, Nagendran J, Lopaschuk GD, et al: Resveratrol prevents hypertension and cardiac hypertrophy in hypertensive rats and mice. Biochim Biophys Acta 1832: 1723-1733, 2013.

35. Chen ZP, Mitchelhill KI, Michell BJ, Stapleton D, Rodriguez-Crespo I, Witters LA, Power DA, Ortiz de Montellano PR and Kemp BE: AMP-activated protein kinase phosphorylation of endothelial NO synthase. FEBS Lett 443: 285-289, 1999.

36. Zhang J, Xie Z, Dong Y, Wang S, Liu C and Zou MH: Identification of nitric oxide as an endogenous activator of the AMP-activated protein kinase in vascular endothelial cells. J Biol Chem 283: 27452-27461, 2008. 